\title{
High-intensity focused ultrasound therapy in combination with gemcitabine for unresectable pancreatic carcinoma
}

This article was published in the following Dove Press journal:

Therapeutics and Clinical Risk Management

2 May 2016

Number of times this article has been viewed

Wei Lv

Tao Yan

Guojin Wang

Wei Zhao

Tao Zhang

Dinghua Zhou

Hepatobiliary Surgery Department, Second Artillery General Hospital,

Xicheng District, Beijing, People's

Republic of China
Correspondence: Dinghua Zhou Hepatobiliary Surgery Department, Second Artillery General Hospital,

The New Main Street 16th, Xicheng

District, Beijing 100088, People's

Republic of China

Tel +86 I0 66343474

Fax +86 I0 66343099

Email zhou_dinghual23@I26.com
Objective: To investigate the therapeutic effect and safety of high-intensity focused ultrasound (HIFU) therapy combined with gemcitabine in treating unresectable pancreatic carcinoma.

Methods: The 45 patients suffering from pancreatic carcinoma were randomized into two groups. The patients in the experimental group $(n=23)$ received HIFU in combination with gemcitabine and those in the control group $(n=22)$ received gemcitabine alone. The effect and clinical benefit rates in the two groups were compared. The median survival time and 6-month and 12-month survival rates were calculated by Kaplan-Meier method and log-rank test.

Results: The median survival time and 6-month survival rate were significantly higher in the experimental group than in the control group ( 8.91 months vs 5.53 months, $73.9 \%$ vs $40.9 \%$, respectively $P<0.05$ ), but 12 -month survival rate was not statistically different between the two groups $(13.0 \%$ vs $4.5 \%, P>0.05)$. The clinical benefit rates in the experimental group and the control group were $69.6 \%$ and $36.3 \%$, respectively $(P<0.05)$. The pain remission rate in the experimental group was significantly higher than that in the control group ( $65.2 \%$ vs $31.8 \%, P<0.05)$.

Conclusion: HIFU in combination with gemcitabine is better than gemcitabine alone. This combinatorial therapy may become a better and effective treatment for unresectable pancreatic carcinoma.

Keywords: pancreatic carcinoma treatment, high-intensity focused ultrasound therapy, gemcitabine

\section{Introduction}

Pancreatic cancer is one of the most common digestive tract malignant tumors with an increasing morbidity in the whole world. By 2030, it is expected to be the second leading cause of cancer death. ${ }^{1}$ Because of the absence of signs and symptoms in the early stage, $80 \%$ of the patients are in the terminal stage of pancreatic cancer when diagnosed. One study demonstrated that only $7 \%$ of pancreatic cancers are considered as a localized disease at diagnosis. ${ }^{2}$ During this state, the median survival time is only 3-6 months. ${ }^{3}$ The symptoms are nonspecific, such as nausea, anorexia, jaundice, and weight loss and abdominal pain, leading to difficulties and misleading in the diagnosis. ${ }^{4}$ The only curative management option for pancreatic cancers is surgical resection. However, only $15 \%-25 \%$ of patients have a surgically resectable tumor at diagnosis. ${ }^{5}$ High-intensity focused ultrasound (HIFU) therapy has been used to treat several diseases, such as symptomatic uterine fibroids ${ }^{6}$ and adenomyosis. ${ }^{7}$ Thus, in order to improve the patients' general condition and the survival rate, we use HIFU surgery combined with gemcitabine chemotherapy to treat the pancreatic cancer that cannot be surgically resected. Our study provides an effective and safe way to treat the unresectable pancreatic cancer. 


\section{Materials and methods}

\section{Patients}

This study was reviewed and approved by the ethics committee of Second Artillery General Hospital. All the patients provided informed consent and agreed to take part in the study. We randomly selected 45 patients with pancreatic cancer, which could not be surgically resected at the Second Artillery General Hospital from March 2008 to January 2011. There were 28 males and 17 females aged from 26 years to 71 years. The median age was 59.3 years, and there were 22 cases of pancreatic head carcinomas, and 23 cases of carcinomas of pancreatic body and tail. From the abdomen computed tomography/magnetic resonance imaging, we found that the smallest tumor was $2.6 \mathrm{~cm} \times 2.5 \mathrm{~cm} \times 1.8 \mathrm{~cm}$ and the largest tumor was $8.1 \mathrm{~cm} \times 7.5 \mathrm{~cm} \times 5.8 \mathrm{~cm}$. The Union for International Cancer Control staging criteria III period involved 29 cases and criteria IV period 16 cases. The inclusion criteria included the following: 1) confirmed by pathological histology or cytology or with typical clinical manifestations combined with imageological examination and tumor marker CA-199 test; 2) patients with the measurable and valuable lesions on the imaging such as abdominal pain and (or) waist pain, loss of appetite, and weight loss ( $>15 \%$ ); 3) lost opportunities of surgery contraindications; 4) well physical condition (Karnofsky Performance Status score $>70$ ), no obvious ascites and jaundice, and expected survival time $>3$ months; and 5) normal routine blood and kidney function and no significant differences between the two groups $(P>0.05)$. Expected observation and the follow-up time were at least 12 months.

\section{HIFU therapy}

The experimental group patients received HIFU treatment, and the equipment was produced by Chongqing Haifu Technology Co., Ltd. This equipment was JC200 type HIFU tumor treatment system. With the help of this equipment, we can identify body surface location and develop a plan of treatment according to the image of the tumor. During the surgery, we can compare the target image and gray value and observe the lesions to identify the coagulation necrosis. Treatment parameters include frequency $0.97 \mathrm{MHz}$, focus $147 \mathrm{~mm}$, layer number of treatments 20-30, treatment layer spacing $5 \mathrm{~mm}$, therapeutic range $80 \%-100 \%$, average total treatment time 1,560 seconds, average power $350 \mathrm{~W}$, and overall average energy $725,000 \mathrm{~J}$. The experimental group patients were expected to accept a single treatment; additional treatment can be added when necessary.

\section{Gemcitabine application}

Gemzar (domestic gemcitabine booster injection from Lilly Suzhou Pharmaceutical Company) is given by infusion through a vein (intravenously) once a week. Three doses were given as a whole treatment cycle. The two groups of patients accepted at least two cycles of chemotherapy. In the experimental group, patients were observed for 3 days after HIFU surgery. If there are no special complications, we continue to apply the gemcitabine chemotherapy.

\section{Disease-related symptom improvement}

Disease-related symptom improvement is a comprehensive assessment of pain, performance status, and weight change. It is the same as clinical benefit response. Evaluation criteria include: 1) the daily decreased dosage of analgesic drugs $\geq 50 \% ; 2$ ) relieve pain $\geq 50 \%$ (the daily assessment was conducted using Memorial Pain Assessment Card); 3) physical conditions improvement $\geq 20$ scores (the daily assessment was conducted using Karnofsky); and 4) the above three evaluation indicators were stable and weight gain $\geq 7 \%$. If the patients improved more than one index above for $>4$ weeks and there is no other deterioration indicator, the patient is a clinical benefit case.

\section{Objective curative effect of tumor}

According to Response Evaluation Criteria In Solid Tumor curative effect evaluation standard, the objective curative effect of tumor can be divided into complete remission (CR; all tumor lesions disappeared for $>4$ weeks), partial remission (PR; the max tumor diameter reduced by $30 \%$ for $>4$ weeks), stable disease (SD; changes between PR and progression of disease [PD]), and PD the sum of the single largest diameter increased by $20 \%$ or a new lesion) ${ }^{8,9}$ Disease control rate $=\mathrm{CR}+\mathrm{PR}+\mathrm{SD}$.

\section{Survival time}

Median survival time (MST) is the median time from treatment to death. Survival time is the date from treatment to death or the second day after death. During the follow-up period, we use all of the data for the survival patients and the data from the start of the follow-up to the day when the patients died.

\section{HIFU complications and chemotherapy toxicity}

We separated the adverse reaction of chemotherapy to I-IV degrees according to World Health Organization and did safety assessment of the experimental group with HIFU ablation.

\section{Statistical analysis}

All the data were analyzed by SPSS 17.0. We used KaplanMeier method for survival analysis and calculate the 6- and 
Table I CBR comparison after treatment

\begin{tabular}{lllllll}
\hline Groups & $\mathbf{n}$ & $\begin{array}{l}\text { Pain relief } \\
(\mathbf{n})\end{array}$ & $\begin{array}{l}\text { Reduction in the use } \\
\text { of pain killers }(\mathbf{n})\end{array}$ & $\begin{array}{l}\text { Improvement in } \\
\text { physical strength (n) }\end{array}$ & $\begin{array}{l}\text { Weight gain } \\
\text { Effective rate } \\
\text { (\%) }\end{array}$ \\
\hline Experimental group & 23 & 15 & 16 & 8 & 0 & 69.6 \\
Control group & 22 & 7 & 8 & 4 & 0 & 36.3 \\
\hline
\end{tabular}

Abbreviation: CBR, clinical benefit rate.

12-month survival rates and the MST. We also used log-rank test to compare the statistical difference. Enumeration data were tested by $\chi^{2}$ test. $P<0.05$ meant significant difference.

\section{Results}

\section{Clinical benefit rate}

As shown in Table 1, the total effective rate of HIFU combined with gemcitabine in the experimental group (23 patients) was $69.6 \%$, while that in the control group that only accepted HIFU therapy (22 patients) was $36.3 \%$. There is a significant difference between the two groups $\left(\chi^{2}=4.98\right.$; $P<0.05$ ). Analysis showed that the pain relief rate of HIFU combined with the gemcitabine in the experimental group was $65.2 \%$, and it was better than that in the group that used only gemcitabine chemotherapy with the pain relief rate of $31.8 \%\left(\chi^{2}=5.01 ; P<0.05\right)$.

\section{Disease control rate}

Among the 45 patients, there was no CR. In the experimental group, ten patients reached PR and eight patients reached SD. The disease control rate was $78.2 \%$. Among the 22 patients in the control group, four patients reached PR and nine patients reached SD. The disease control rate was $59.0 \%$. There was no significant difference between the two groups $\left(\chi^{2}=1.92 ; P>0.05\right)$.

\section{Survival analysis of patients with pancreatic cancer}

As shown in Table 2 and Figure 1, the MST in the experimental group (23 patients) was 8.91 months and the accumulative survival rates of 6 months and 12 months was $73.9 \%$ and $13.0 \%$, respectively. The MST in the control group (22 patients) was 5.53 months, and the accumulative survival rates of 6 months and 12 months were $40.9 \%$ and $4.5 \%$, respectively. There was significance difference between the

Table 2 Comparison of survival rate

\begin{tabular}{lllllll}
\hline Groups & $\mathbf{n}$ & \multicolumn{2}{c}{ 6-month survival } & & I2-month survival \\
\cline { 3 - 4 } & & Cases & $\begin{array}{c}\text { Survival } \\
\text { rate (\%) }\end{array}$ & & Cases & $\begin{array}{c}\text { Survival } \\
\text { rate (\%) }\end{array}$ \\
\hline Experimental group & 23 & 17 & 73.9 & 3 & 13.0 \\
Control group & 22 & 9 & 40.9 & & 4.5 \\
\hline
\end{tabular}

two groups in the 6-month survival time $\left(\chi^{2}=5.10 ; P<0.05\right)$, while there was no significance difference between the two groups in the 12-month survival time $\left(\chi^{2}=0.22 ; P>0.05\right)$.

\section{Adverse reaction and safety observation HIFU-dependent adverse reaction}

All 23 patients in the experimental group who accepted HIFU showed the skin was warm to touch and that disappeared after 3 to 4 days. All patients did not present skin burns, pancreatic fistula, gastrointestinal perforation, pancreatitis, or other serious complications.

\section{Chemotherapy-related adverse reactions}

Chemotherapy-related adverse reactions mainly included the blood system toxicity and gastrointestinal reaction. Among the 23 experimental group patients, eight patients showed I leukopenia, three patients showed II leucopenia, and four patients showed III leukopenia. In the control group, among 22 patients, five patients showed I leukopenia, four patients showed II leucopenia, and four patients showed III leukopenia. The two groups did not show fourth degree adverse reactions, and there was significant difference between the two groups $\left(\chi^{2}=0.179 ; P>0.05\right)$. The main gastrointestinal reactions were severe nausea and vomiting, and overall, the patients were able to tolerate. There were no patients who did not complete chemotherapy.

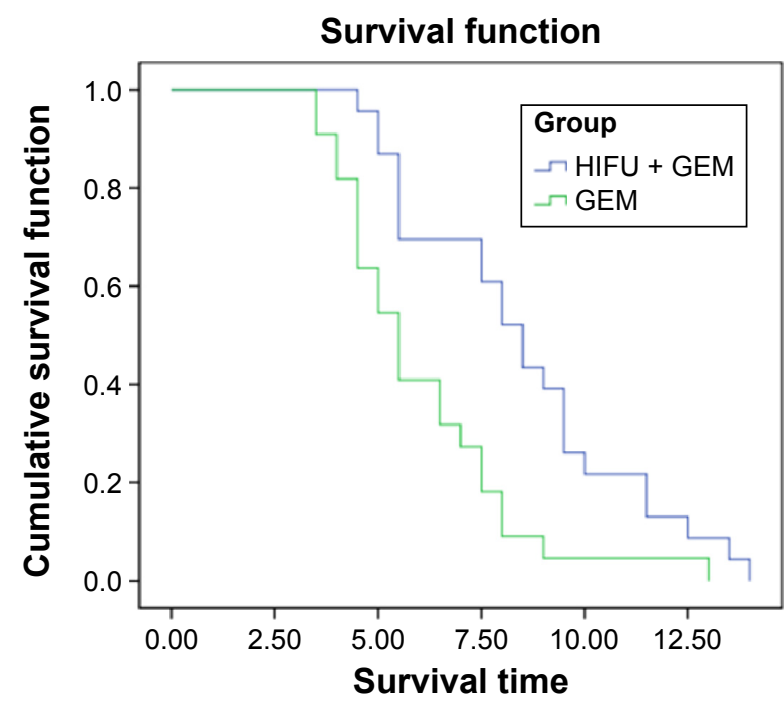

Figure I Comparison of survival curve between two groups. Abbreviations: HIFU, high-intensity focused ultrasound; GEM, gemcitabine. 


\section{Discussion}

Patients with pancreatic cancer are increasing all over the world. In our country, the annual incidence of pancreatic cancer is $\sim 5.1 / 100,000$, which is three times larger than that 20 years ago.${ }^{10}$ Because of the characteristics of the anatomy, pancreatic cancer is hard to discover in clinical diagnosis. In all, $80 \%$ of patients cannot undergo radical resection surgery once diagnosis is confirmed. For now, increased overall survival rate and quality of life are the goals for patients with pancreatic cancer, and pain management is the key point. Gemcitabine as the main drug of chemotherapy cannot relieve pain, and hence, it is not useful to increase patients quality of life. Palliative treatment of pancreatic cancer is an ongoing challenge in patient care.

The application of ultrasound in tumor treatment has a history of 50 years. Now, it has developed into the ultrasonic surgical technique - HIFU. ${ }^{11}$ HIFU uses penetrability and focusability of ultrasound to produce a heat effect in the tumor area. It causes the target area to reach $65^{\circ} \mathrm{C}-100^{\circ} \mathrm{C}$ immediately and leads to protein denaturation and coagulation necrosis. It leads to irreversible damage. ${ }^{12}$ In addition to thermal effects, HIFU can also produce mechanical effect and cavitation effect. Because the tumor invades the superior mesenteric vein and portal vein, surgery is high risk, most patients are therefore unable to be treated surgically. According to the research in $2000,{ }^{13,14}$ HIFU will not have large effects on blood vessels with a diameter $>200 \mu \mathrm{m}$, while it will only block the vasa vasorum with a diameter $<200 \mu \mathrm{m}$. These properties became the foundation of ablation therapy to advanced pancreatic cancer. Severe back pain is thought to be associated with tumor invasion to plexus around abdominal and retroperitoneal. ${ }^{15}$ The mechanism of HIFU relief pain is that HIFU can lead to damage in the pancreas and around solar plexus when treating pancreatic tumors. Early results showed that HIFU can stimulate the body's immune system. ${ }^{16}$ Gemcitabine is a kind of cell cycle drug resistant to metabolism, and it is the only drug approved by the US Food and Drug Administration to treat advanced pancreatic cancer. Now, gemcitabine has become the first-line agent to treat pancreatic cancer both in People's Republic of China and abroad. ${ }^{17}$ The criteria III period test shows that there is no difference between the gemcitabine treatment with or without cisplatin. ${ }^{18}$ The efficiency of gemcitabine in pancreatic cancer treatment is $20 \%-30 \%$, MST is 4.2 months -5.5 months, and 1-year survival rate is $<16 \%-19 \% .{ }^{18-20} \mathrm{HIFU}$ as a kind of heat treatment combined with chemotherapy makes it easy for the drugs to enter local tumor cell. Through this, it can improve the drug concentration in the cell and therapeutic efficacy of drugs theoretically. There is a synergy between heat treatment and chemotherapy, and the specific mechanism may be that HIFU in local high temperature changed the tumor cell membrane permeability. ${ }^{21}$

The results of the study show that HIFU ablation combined with gemcitabine static drop after chemotherapy can significantly improve survival rates of 6 months $(73.9 \%$ vs $40.9 \%$, $P<0.05$ ), but not 12 months ( $13.0 \%$ vs $4.5 \%, P>0.05$ ), when compared to the pure gemcitabine chemotherapy, which indicates that combination therapy did not improve the 1-year survival rate. With respect to the disease control rates, the experimental group (78.2\%) had higher value than the control group $(59.0 \%)$, but not statistically different $(P>0.05)$, similar to that reported in the literature, which indicates that combination therapy has no obvious advantage in disease control. The two groups showed significant differences in abdominal pain remission rate, showing that HIFU ablation plays a dominant role in pain relief and is better than that of pure gemcitabine chemotherapy in improving patients' quality of life. In terms of safety, the experimental group patients after HIFU ablation just have a felling of warmth but not serious complications besides those affecting the area of skin, and in the two groups, there were no seriously related adverse reactions to chemotherapy, and hence, there was no statistically significant difference $(P<0.05)$.

\section{Conclusion}

In conclusion, HIFU combined gemcitabine chemotherapy is better than gemcitabine in inoperable pancreatic cancer. It can improve the quality of life and prolong the survival time. There is no serious adverse reaction, and it is a good palliative treatment. However, there are some problems worth noting. Is it because of heat treatment effect, that the HIFU combined gemcitabine chemotherapy works better than gemcitabine? HIFU can reduce the dose of gemcitabine after surgery in order to relieve the pain in the patients with chemotherapy and the best time to use chemotherapy drugs is after HIFU surgery. It is worthy for clinical attention and carrying out the experiments of further research.

\section{Disclosure}

The authors report no conflicts of interest in this work.

\section{References}

1. Kim VM, Ahuja N. Early detection of pancreatic cancer. Chin J Cancer Res. 2015;27:321-331.

2. Jemal A, Siegel R, Ward E, Hao Y, Xu J, Thun MJ. Cancer statistics, 2009. CA Cancer J Clin. 2009;59:225-249.

3. Xiong LL, Hwang JH, Huang XB, et al. High intensity focused ultrasound treatment. Chin J Med Ultrasound. 2007;17(4):15-18. 
4. Badger SA, Brant JL, Jones C, et al. The role of surgery for pancreatic cancer: a 12-year review of patient outcome. Ulster Med J. 2010; 79:70-75.

5. Goodman MD, Saif MW. Adjuvant therapy for pancreatic cancer. JOP. 2014;15:87-90.

6. Ikink ME, van Breugel JM, Schubert G, et al. Volumetric MR-guided high-intensity focused ultrasound with direct skin cooling for the treatment of symptomatic uterine fibroids: proof-of-concept study. Biomed Res Int. 2015;2015:684250.

7. Xiong Y, Yue Y, Shui L, Orsi F, He J, Zhang L. Ultrasound-guided high-intensity focused ultrasound (USgHIFU) ablation for the treatment of patients with adenomyosis and prior abdominal surgical scars: a retrospective study. Int J Hyperthermia. 2015;14:1-7.

8. Yoshida S, Miyata Y, Ohtsu A, et al. Significance of and problems in adopting response evaluation criteria in solid tumor RECIST for assessing anticancer effects of advanced gastric cancer. Gastric Cancer. 2000;3(3):128-133.

9. Forner A, Ayuso CM, Rimola J, et al. Evaluation of tumor response after locoregional therapies in hepatocellular carcinoma: are response evaluation criteria in solid tumors reliable? Cancer. 2009;115(3):616-623.

10. Zhang QH, Ni QX. Clinical analysis of 2340 cases of pancreatic cancer. Chin Med J. 2004;84(3):214-218.

11. Wu F. Ultrasound therapy. Ultrasound Clin Med. 2000;2:189-190.

12. Ter HG. Therapeutic ultrasound. Eur J Ultrasound. 1999;9:3-9.

13. Kennedy J, Ter Haar G, Cranston D. High intensity focused ultrasound: surgery of the future? Brit J Radiol. 2003;76(909):590.
14. Hynynen K, Chung AH, Colucci V, Jolesz FA. Potential adverse effects of high-intensity focused ultrasound exposure on blood vessels in vivo. Ultrasound Med Biol. 1996;22(2):193-201.

15. Zech DF, Grond S, Lynch J, Hertel D, Lehmann KA. Validation of World Health Organization guidelines for cancer pain relief: a 10-year prospective study. Pain. 1995;63(1):65-76.

16. Dubinsky TJ, Cuevas C, Dighe MK, Kolokythas O, Hwang JH. High-intensity focused ultrasound: current potential and oncologic applications. Am J Roentgenol. 2008;190(1):191-199.

17. Zhu XJ, Su L. Local radiotherapy combined with gemcitabine chemotherapy for pancreatic cancer in 21 cases. Shandong Tradit Chin Med. 2010;50(006):54-54.

18. Heinemann V, Quietzsch D, Gieseler F, et al. Randomized phase III trial of gemcitabine plus cisplatin compared with gemcitabine alone in advanced pancreatic cancer. J Clin Oncol. 2006;24(24):3946.

19. Prost P, Ychou M, Azria D. Gemcitabine and pancreatic cancer. B Cancer. 2002;89:91.

20. Herrmann R, Bodoky G, Ruhstaller T, et al; Swiss Group for Clinical Cancer Research; Central European Cooperative Oncology Group. Gemcitabine plus capecitabine compared with gemcitabine alone in advanced pancreatic cancer: a randomized, multicenter, phase III trial of the Swiss Group for Clinical Cancer Research and the Central European Cooperative Oncology Group. J Clin Oncol. 2007;25(16):2212.

21. Zeng QD, Lv LH, Zhang XH. Clinical study of high intensity focused ultrasound combined with gemcitabine in patients with advanced pancreatic cancer. Chin J Hepatobiliary Surg. 2006;12(011):748-750.
Therapeutics and Clinical Risk Management

\section{Publish your work in this journal}

Therapeutics and Clinical Risk Management is an international, peerreviewed journal of clinical therapeutics and risk management, focusing on concise rapid reporting of clinical studies in all therapeutic areas, outcomes, safety, and programs for the effective, safe, and sustained use of medicines. This journal is indexed on PubMed Central, CAS,

\section{Dovepress}

EMBase, Scopus and the Elsevier Bibliographic databases. The manuscript management system is completely online and includes a very quick and fair peer-review system, which is all easy to use. Visit http://www.dovepress.com/testimonials.php to read real quotes from published authors.

Submit your manuscript here: http://www.dovepress.com/therapeutics-and-clinical-risk-management-journal 